\title{
Originals
}

\section{Genetic and metabolic studies in diabetic neuropathy}

\author{
A.J.M. Boulton ${ }^{1}$, R.C. Worth ${ }^{1}$, J. Drury ${ }^{1}$, C.A. Hardisty ${ }^{1}$, E. Wolf ${ }^{2}$, A. G. Cudworth ${ }^{2 \dagger}$ and J.D. Ward ${ }^{1}$ \\ ${ }^{1}$ Royal Hallamshire Hospital, Sheffield and ${ }^{2}$ St. Bartholomew's Hospital, London, UK
}

\begin{abstract}
Summary. Forty-one diabetic patients with symptomatic diabetic neuropathy were studied together with an equal number of matched diabetic subjects without neuropathy. The acetylator status was determined and HLA-A, B, C and DR antigens were investigated. Metabolic control was assessed by measurement of glycosylated haemoglobin and by the mean of multiple random clinic blood glucose values. No significant difference was observed between the two groups in the proportion of fast and slow acetylators. The distribution of HLA frequencies was similar in subjects with and without neuropathy for both Type 1 (insulin-dependent) and Type 2 (non-insulin-dependent) diabetic patients. When compared with diabetic subjects without neuropathy, the neuropathy group had
\end{abstract}

higher levels of both glycosylated haemoglobin (mean \pm SEM: $50.1 \pm 1.4$ versus $57.5 \pm 1.8 \mathrm{mmol}$ hydroxymethylfurfu$\mathrm{ral} / \mathrm{mol}$ haemoglobin $(10.5 \pm 0.3$ versus $12.0 \pm 0.4 \%$ haemoglobin $\left.\mathrm{A}_{1}, p<0.01\right)$ and mean blood glucose $(9.3 \pm 0.4$ versus $11.3 \pm 0.5 \mathrm{mmol} / 1, p<0.005)$. This study provides no evidence that genetic factors increase the susceptibility of diabetic patients to develop neuropathy. In contrast, the elevated glycosylated haemoglobin and blood glucose levels strengthen the association between hyperglycaemia and diabetic neuropathy.

Key words: Diabetes mellitus, diabetic neuropathies, genetics, acetylation, histocompatibility antigens, glycosylated haemoglobin, diabetic control, blood glucose.
Peripheral neuropathy is the commonest long-term complication amongst the diabetic population [1], but its aetiology remains unclear $[2,3]$. Studies both in animals [4] and man [5, 6] have suggested that poor blood glucose control plays an important part in the development of peripheral nerve damage, although there have been reports of cases of neuropathy which were apparently precipitated by the introduction of strict glucoregulation [7, 8]. A relationship between impaired nerve conduction velocities and hyperglycaemia has been demonstrated for both Type 1 (insulin-dependent) [9] and Type 2 (non-insulin-dependent) diabetes [10]. In clinical practice, paradoxically, some poorly controlled diabetic patients never develop symptomatic neuropathy while, conversely, other diabetic patients develop neuropathy despite seemingly good blood glucose control. Thus, it has been suggested that genetic factors may be a further mechanism influencing the susceptibility of diabetic patients to develop complications [11].

The rate of acetylation of certain drugs, such as isoniazid and the sulphonamides, is genetically determined [12], and individuals may be classed as 'fast' or 'slow' acetylators. Whereas slow acetylators are more likely to develop peripheral neuropathy when treated with isoniazid, McLaren et al, in a study of diabetic patients with and without neuropathy, suggested that fast acetylators may be protected against peripheral neuropathy [13]. More recent studies, however, have failed to confirm this observation $[14,15]$. There has also been conflicting evidence regarding the relationship between HLA genetic factors and the microvascular complications of diabetes [16-18], although, to our knowledge, there have been no such studies in patients with neuropathy.

We therefore selected two groups of diabetic patients to investigate the relationship between genetic factors and neuropathy, using glycosylated haemoglobin and multiple blood glucose measurements to provide indices of the quality of blood glucose control.

\section{Patients and methods}

\section{Patients}

The study population consisted of 82 patients, 41 with and 41 without symptomatic diabetic neuropathy. The two groups were matched for age, sex, type and duration of diabetes (Table 1). Each group consisted of 29 male and 12 female patients and included 20 subjects with 
Table 1. Clinical details of subjects with and without neuropathy

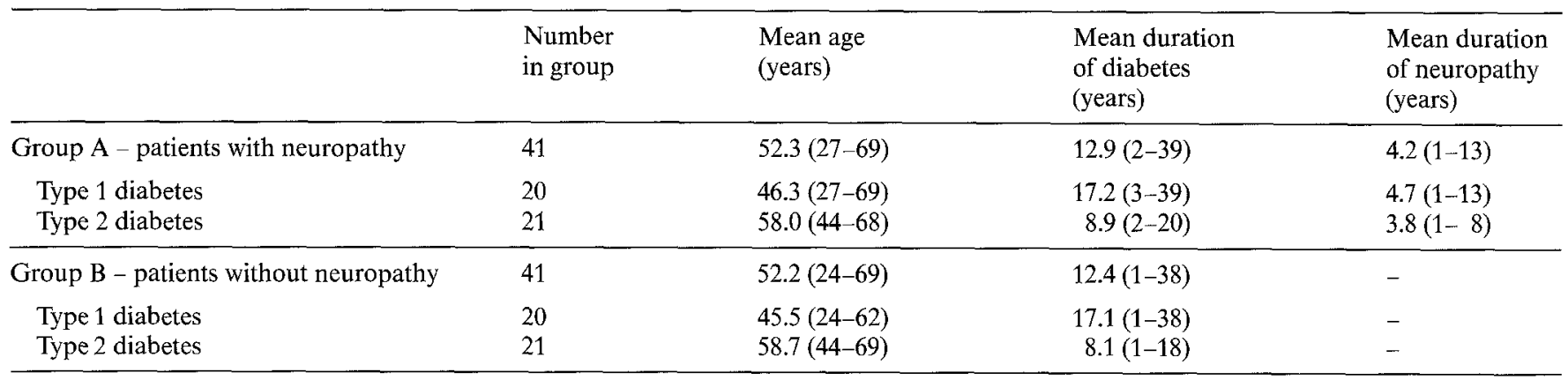

Ranges given in parentheses

Type 1 and 21 with Type 2 diabetes. All were Caucasoid subjects from the Sheffield area and gave informed consent to the studies which were approved by the Hospital Ethical Committee.

Group A consisted of 41 subjects with neuropathy and painful symptoms in both legs (paraesthesiae, burning pains or cramps, with symptoms more pronounced nocturnally) for at least one year before the study, or a history of such symptoms together with neuropathic foot ulceration. Patients with symptomatic neuropathy also satisfied the following criteria: (a) motor conduction velocity (MCV) (peroneal nerve) $<42 \mathrm{~m} / \mathrm{s}$. The mean $\mathrm{MCV} \pm \mathrm{SEM}$ was $31.6 \pm 1.0 \mathrm{~m} / \mathrm{s}$ (range $20-41 \mathrm{~m} / \mathrm{s}$ ). Values were unrecordable in seven patients and they were assigned a result $1 \mathrm{~m} / \mathrm{s}$ lower than the slowest $\mathrm{MCV}$ in the group for statistical analysis; (b) absent ankle jerks; (c) no clinical or ultrasound evidence of peripheral vascular disease (ankle pressure index greater than unity) [19].

Group B consisted of 41 diabetic subjects without symptoms of neuropathy or peripheral vascular disease. All had normal peripheral pain sensation, foot pulses, ankle pressure indices greater than unity and subjects under 60 years of age had preserved ankle jerks. The mean MCV (peroneal nerve) was $42.7 \pm 0.7 \mathrm{~m} / \mathrm{s}$ (range 37-57). A full neurophysiological characterisation of both patient groups has been described previously [20].

Subjects were selected without prior knowledge of the quality of their diabetic control. A small proportion of each group had diabetic retinopathy on fundal examination. With the exception of one subject in group A who had a serum creatinine concentration of $210 \mu \mathrm{mol} / 1$, all other patients had concentrations $<125 \mu \mathrm{mol} / \mathrm{l}$.

\section{Methods}

\section{HLA studies}

Citrated blood taken for HLA genetic studies was transported in tissue culture medium 199 (Wellcome). All samples were received within $24 \mathrm{~h}$ of venesection. Typing for all recognised HLA-A, B and C antigens was performed using a modified microlymphocytotoxicity technique [21] and for HLA-DR antigens by a two colour fluorescence technique [22]. DR typing was only possible in 66 out of the 82 subjects for technical reasons.

\section{Acetylator status}

The acetylator phenotype was determined by the method of Evans [23]. Fasting subjects were given $750 \mathrm{mg}$ of sulphadimidine orally. Samples were taken $6 \mathrm{~h}$ after drug ingestion and serum was stored at $-20^{\circ} \mathrm{C}$ until analysis. Those with $<60 \%$ of the drug as the acetylated metabolite were classified as 'slow acetylators', the rest as 'fast acetylators'. This investigation was performed on only 79 patients, since three were probably allergic to sulphonamides.

\section{Glycosylated haemoglobin}

Glycosylated haemoglobin levels were measured by a colorimetric technique based on the method of Fluckiger and Winterhalter [24]. Blood was collected into lithium heparin tubes and the red cells washed twice in physiological saline. The cells were lysed and the haemoglobin concentration standardised at $8.25 \mathrm{mmol} / \mathrm{l}$. The sample was heated at $100^{\circ} \mathrm{C}$ for $6 \mathrm{~h}$ with oxalic acid to liberate 5-hydroxymethylfurfural (HMF). The concentration of HMF was estimated colorimetrically by condensation with thiobarbituric acid using Technicon AA1 autoanalyser equipment (Technicon Instruments, Basingstoke, UK). The method was standardised using aqueous HMF solutions, these standards being taken through the complete analytical procedure. The reactions involved are non-stoichiometric and require precise control of the reaction conditions. These rigorous requirements are met by the use of our semi-automated approach. The between batch coefficient of variation obtained during this study was $5.8 \%$ and our normal range is $29-39 \mathrm{mmol} \mathrm{HMF} / \mathrm{mol}$ haemoglobin (6.3-8.3\% haemoglobin $A_{1}$ ). The results obtained by this method correlated very closely $(y=0.2 \times+0.5, r=0.92, p<0.001)$ with those of a temperature-controlled microcolumn ion-exchange technique (Bio-Rad Haemoglobin Al Column Test). The subject with an elevated serum creatinine was excluded from the analysis of glycosylated haemoglobin results because of the presence of renal failure, which may invalidate the results [25]. Another patient with neuropathy failed to provide a sample for analysis and thus results are included for 19 pairs of Type 2 subjects.

\section{Blood glucose}

The mean blood glucose levels for each group were calculated from the mean of random samples previously obtained at routine diabetic clinic attendances provided that there were six or more samples available for any given patient. Values were available in 34 patients without neuropathy (mean 26 samples/patient, range 6-50) and in 23 subjects with neuropathy (mean 21 samples/patient, range 6-56). Fewer values were available in the neuropathy group because many of these patients presented with this complication.

\section{Statistical analysis}

Results were analysed using the Wilcoxon's signed rank test and the $\mathrm{X}^{2}$ test. Differences in mean blood glucose were analysed using the Mann-Whitney U-test. Results are expressed as mean \pm SEM and the level of significance was set at $p<0.05$. 
Table 2. HLA-A, B, C and DR antigen frequencies in Type 1 diabetic patients in the present series with frequencies from a previously published series

\begin{tabular}{|c|c|c|c|}
\hline \multirow{3}{*}{$\begin{array}{l}\text { HLA-A, B, C } \\
\text { and DR } \\
\text { antigens }\end{array}$} & \multicolumn{3}{|c|}{ Antigen frequencies (\%) } \\
\hline & \multicolumn{2}{|l|}{ Present series } & \multirow{2}{*}{$\begin{array}{l}\text { Type } 1 \\
\text { diabetes } \\
{[26]^{b}}\end{array}$} \\
\hline & $\begin{array}{l}\text { Patients with } \\
\text { neuropathy }\end{array}$ & $\begin{array}{l}\text { Patients without } \\
\text { neuropathy }\end{array}$ & \\
\hline & $(n=19)^{\mathrm{a}}$ & $(n=20)$ & $(n=122)$ \\
\hline $\mathrm{A} 1$ & 47 & 30 & 54 \\
\hline $\mathrm{A} 2$ & 63 & 75 & 66 \\
\hline B8 & 47 & 35 & 60 \\
\hline BW62 & 26 & 35 & 38 \\
\hline CW3 & 32 & 40 & 56 \\
\hline \multirow[t]{2}{*}{ CW7 } & 58 & 65 & 80 \\
\hline & $(n=17)^{\mathrm{c}}$ & $(n=16)^{c}$ & $(n=122)$ \\
\hline DR2 & 12 & 6 & 4 \\
\hline $\mathrm{DR} 3$ & 41 & 44 & 78 \\
\hline $\mathrm{DR} 4$ & 65 & 75 & 83 \\
\hline DR7 & 18 & 13 & 6 \\
\hline DR3, DR4 & 18 & 19 & 51 \\
\hline $\mathrm{DR} 3, \mathrm{DR}^{*}$ & 23 & 25 & 20 \\
\hline $\mathrm{DR} 4, \mathrm{DR}^{*}$ & 47 & 56 & 27 \\
\hline $\mathrm{DR}^{*}, \mathrm{DR}^{*}$ & 12 & 0 & 3 \\
\hline
\end{tabular}

${ }^{\mathrm{a}}$ Results not available from one patient for technical reasons; ${ }^{\mathrm{b}}$ see text; ${ }^{\circ}$ DR typing only available on 33 of the 40 Type 1 diabetic patients for technical reasons; $D^{*}$ denotes either DR1, DR2, DR5, DRW6, DR7, DRW8, DRW9, DRW10 or no DR antigen detected

Table 3. Acetylator phenotypes of subjects with and without neuropathy

\begin{tabular}{llllll}
\hline & \multicolumn{2}{l}{ Acetylator status } & \\
\cline { 5 - 6 } \cline { 5 - 6 } \cline { 5 - 6 } & Fast & & & Slow \\
\cline { 2 - 3 } \cline { 5 - 6 } & No & $(\%)$ & & No & $(\%)$ \\
\hline $\begin{array}{l}\text { Group A - Patients with } \\
\text { neuropathy }\end{array}$ & 18 & 46 & & 21 & 54 \\
$\begin{array}{l}\text { Group B - Patients without } \\
\text { neuropathy }\end{array}$ & 13 & 33 & & 27 & 67 \\
\hline
\end{tabular}

$\chi^{2}=1.46 ; p=$ not significant

\section{Results}

\section{HLA genetic studies}

In the Type 1 diabetic patients, there were no significant differences between the groups with or without neuropathy with respect to the frequencies of any of the HLA$\mathrm{A}, \mathrm{B}$ or $\mathrm{C}$ antigens tested (Table 2 ) and the frequencies did not differ significantly from a previously described large group of Type 1 diabetic patients [26]. Similarly, there were no significant differences between the two groups of Type 1 patients with respect to HLA-DR antigens (Table 2). When compared with a large population of Type 1 diabetic subjects, however, there was a higher, though non-significant, incidence of DR2 amongst the control subjects and those with neuropathy in this study
[26]. The occurrence of DR2 was always in combination with either DR3 or DR4.

In the Type 2 diabetic patients with neuropathy and control patients there was no disturbance of any of the HLA-A, B, C or DR antigen frequencies.

\section{Acetylator status}

The results of the acetylator status are shown in Table 3. There were no significant differences in acetylator phenotypes between patients with neuropathy (Type 1 or Type 2 diabetes) and control subjects.

\section{Glycosylated haemoglobin levels}

Glycosylated haemoglobin levels in the patients with neuropathy $[57.5 \pm 1.8 \mathrm{mmol} \mathrm{HMF} / \mathrm{mol} \mathrm{Hb}(12.0 \pm$ $0.4 \%$ )] were significantly higher than in the control subjects $[50.1 \pm 1.4 \mathrm{mmol} \mathrm{HMF} / \mathrm{mol} \mathrm{Hb}(10.5 \pm 0.3 \%) p<$ 0.01 ; Table 4]. Type 1 diabetic patients with neuropathy had higher levels than control subjects $[60.8 \pm 2.4$ versus $50.2 \pm 1.6 \mathrm{mmol} \mathrm{HMF} / \mathrm{mol} \mathrm{Hb}(12.7 \pm 0.5$ versus $10.5 \pm 0.3 \%) p<0.01]$ but the difference was not significant for Type 2 patients. When the glycosylated haemoglobin levels in the groups with fast and slow acetylators were compared, no significant differences were seen.

\section{Blood glucose}

The mean blood glucose levels in the combined group with neuropathy $(11.3 \pm 0.5 \mathrm{mmol} / \mathrm{l})$ were significantly higher than in the group without neuropathy $(9.3 \pm$ $0.4 \mathrm{mmol} / 1, p<0.005$ ) (Table 4). Type 1 diabetic patients with neuropathy had higher levels than control subjects $(11.6 \pm 0.5$ versus $9.4 \pm 0.4 \mathrm{mmol} / 1, p<0.01)$, but the difference failed to achieve significance for Type 2 subjects.

\section{Discussion}

There have been many studies of the relationship between genetic factors and microvascular complications. It has been argued that antigens B8 and B15 are associated with microangiopathy $[27,28]$, although there is also considerable evidence to suggest that such an association does not exist $[16,18]$. It has also been suggested that the frequent occurrence of diabetes in patients with Friedriech's ataxia is indirect evidence that genetic factors contribute to the development of neuropathy [29]. This present study, however, provides no support for the hypothesis that HLA genetic factors might influence the disposition to diabetic neuropathy. The occurrence of DR2 in $12 \%$ of Type 1 subjects with neuropathy (in contrast with $4 \%$ of a large series of Type 1 diabetic patients) [26] is probably of little significance as the mean age of onset of diabetes in the present study (29 years 
Table 4. Glycosylated haemoglobin and mean random clinic blood glucose levels in patients with and without neuropathy

\begin{tabular}{|c|c|c|c|c|c|c|c|}
\hline & \multicolumn{4}{|c|}{ Glycosylated haemoglobin } & \multicolumn{3}{|c|}{ Blood glucose } \\
\hline $\begin{array}{l}\text { Type } 1 \text { diabetes } \\
\text { Type } 2 \text { diabetes }\end{array}$ & $\begin{array}{l}20 \\
19\end{array}$ & $\begin{array}{l}60.8 \pm 2.4 \\
54.1 \pm 2.5\end{array}$ & $\begin{array}{l}12.7 \pm 0.5 \\
11.3 \pm 0.5\end{array}$ & $\begin{array}{l}<0.01 \\
\text { NS }\end{array}$ & $\begin{array}{r}16 \\
7\end{array}$ & $\begin{array}{l}11.6 \pm 0.5 \\
10.5 \pm 1.0\end{array}$ & $\begin{array}{l}<0.01 \\
\mathrm{NS}\end{array}$ \\
\hline $\begin{array}{l}\text { Type } 1 \text { diabetes } \\
\text { Type } 2 \text { diabetes }\end{array}$ & $\begin{array}{l}20 \\
19\end{array}$ & $\begin{array}{l}50.2 \pm 1.6 \\
49.9 \pm 2.4\end{array}$ & $\begin{array}{l}10.5 \pm 0.3 \\
10.5 \pm 0.5\end{array}$ & $\begin{array}{l}- \\
-\end{array}$ & $\begin{array}{l}19 \\
15\end{array}$ & $\begin{array}{l}9.4 \pm 0.4 \\
9.3 \pm 0.7\end{array}$ & $\begin{array}{l}- \\
-\end{array}$ \\
\hline
\end{tabular}

Results expressed as mean \pm SEM.

Results for percentage glycosylated haemoglobin were calculated using the regression equation $y=0.2 \times+0.5$ (see text). HMF $=$ hydroxymethylfurfural.

Significance values are shown for the comparison of neuropathy patients with their respective control patients without neuropathy

for the Type 1 diabetic patients with neuropathy) is considerably higher than that in the Barts-Windsor prospective family study [26]. The difference in DR2 frequency in the present series may have arisen from the misclassification of a small number of Type 2 diabetic patients as Type 1 diabetic subjects in view of the difficulties of ascertainment of true insulin dependence. This may also explain the relatively "short" duration of diabetes in some 'Type 1' subjects with neuropathy. In view of the polymorphism of the HLA system, we recognise that the present study is relatively small and it is therefore possible that a true association between neuropathy and HLA antigens has not been detected. Nevertheless, there were no detectable trends in any HLA frequencies to suggest that larger studies would demonstrate significant differences. The criteria for selection in this study were strict and every subject with neuropathy had suffered symptoms for at least 12 months. The lack of any generally acceptable definiton of symptomatic diabetic neuropathy has previously led to a vast variation in the quoted incidence of this complication [3].

The present study showed no significant differences in the proportion of fast and slow acetylators in patients with or without neuropathy. Furthermore, the glycosylated haemoglobin results of the fast acetylators were not significantly different from those of the slow acetylators. We were unable to confirm the earlier findings of McLaren et al. [13] who suggested that there was a higher proportion of fast acetylators amongst the diabetic population without neuropathy. The percentage of fast acetylators in our neuropathy subjects $(46 \%)$ was similar to that recently reported by Bodansky et al. (41\%) [14]. All these studies were of Caucasoid diabetic patients living in the United Kingdom. The recent study of Shenfield et al. [15] from Australia reached the same conclusions but the proportion of fast acetylators amongst neuropathy patients was higher in their study $(57 \%)$.
The lack of an association between genetic factors and the presence of neuropathy was in contrast with the elevated glycosylated haemoglobin and mean blood glucose levels (obtained prior to development of neuropathy) recorded in our affected diabetic patients. It was of interest that the evidence for poor metabolic control in neuropathy patients was confined to Type 1 diabetic subjects. Therefore, the results of this study further emphasise the link between hyperglycaemia and diabetic neuropathy suggested by earlier workers $[5,6]$. Several more recent studies have shown improvement in subjective and objective measurements of nerve function during periods of strict metabolic control $[9,10,30]$.

In conclusion, we have been unable to demonstrate any association between acetylator phenotype or HLA genetic factors and the presence of diabetic peripheral neuropathy. In contrast, these results suggest that hyperglycaemia, or related metabolic abnormalities, are more important factors associated with the development of established neuropathy.

Acknowledgements. Drs. F. J. Flint and D. R. Cullen kindly allowed us to study patients under their care. We thank B. Watson, V. Drummond and V.Algar for their technical assistance with the HLA studies, and J.Ollerenshaw and F. Philips for assessing the acetylator phenotypes. We also thank M. Benton and M. Holden for measuring the glycosylated haemoglobin. We are grateful to Mrs. E. Ward for typing the manuscript. This work was supported by the Marjorie Parsons Diabetic Research Fund.

\section{References}

1. Ellenberg M (1982) Diabetic neuropathy. Compr Ther 8: 21-31

2. Clements RS (1979) Diabetic neuropathy: new concepts of its aetiology. Diabetes 28: 604-611

3. Thomas PK, Ward JD, Watkins PJ (1982) Diabetic neuropathy. In: Keen $\mathbf{H}$, Jarrett $\mathbf{J}$ (eds) Complications of diabetes, 2nd edn. Edward Arnold, London, pp 109-136

4. Greene DA, de Jesus PV, Winegrad AI (1975) Effects of insulin and dietary myoinositol on impaired peripheral motor conduction velocity in acute streptozotocin rats. J Clin Invest 55: 1326-1336 
5. Pirart J (1965) Diabetic neuropathy: a metabolic or a vascular disease. Diabetes 14: 1-9

6. Pirart J (1978) Diabetes mellitus and its degenerative complications: a prospective study of 4400 patients between 1947-1973. Diabetes Care 1: 168-188 and 252-263

7. Ellenberg $M$ (1958) Diabetic neuropathy precipitating after institution of diabetic control. Am J Med Sci 236: 466-471

8. Ellenberg $M$ (1959) Diabetic neuropathy precipitated by diabetic control with tolbutamide. JAMA 169: 1755-1757

9. Pietri A, Ehle AL, Raskin P (1980) Changes in nerve conduction velocity after six weeks of glucoregulation with portable insulin infusion pumps. Diabetes 29:668-671

10. Porte D, Graf RJ, Halter JB, Pfeifer MA, Halar E (1981) Diabetic neuropathy and plasma glucose control. Am J Med 70: 195-200

11. Pyke DA, Tattersall RB (1973) Diabetic retinopathy in identical twins. Diabetes 22: 613-618

12. Lunde PM, Frislid K, Hansteen V (1977) Disease and acetylator polymorphism. Clin Pharmacokinet 2: 182-197

13. McLaren EH, Burden AC, Moorhead PJ (1977) Acetylator phenotype in diabetic neuropathy. $\mathrm{Br}$ Med J 2: 291-293

14. Bodansky HJ, Drury PL, Cudworth AG, Price Evans DA (1981) Acetylator phenotypes and Type 1 (insulin-dependent) diabetics and microvascular disease. Diabetes 30:907-910

15. Shenfield GM, McCann VJ, Tjokuesetio R (1982) Acetylator status and diabetic neuropathy. Diabetologia 22: 441-444

16. Bodansky HJ, Wolf E, Cudworth AG, Dean BM, Nineham LJ, Botazzo GF, Matthews JA, Kurtz AB, Kohner EM (1982) Genetic and immunological factors in microvascular disease in Type 1 (insulin-dependent) diabetes. Diabetes 31: 70-74

17. Dornan TL, Ting A, McPherson CK, Peckar CO, Mann JI, Turner RC, Morris PJ (1982) Genetic susceptibility to the development of retinopathy in insulin-dependent diabetes. Diabetes 31: 226-231

18. Cudworth AG, Bodansky HJ (1982) Genetic and metabolic factors in relation to the prevalence and severity of diabetic complications. In: Keen H, Jarrett $\mathrm{RJ}$ (eds) Complications of diabetes, 2nd Edn. Edward Arnold, London, pp 1-12

19. Yao JST, Hobbs JT, Irvine WT (1969) Ankle systolic pressure measurement in arterial disease affecting the lower extremities. Br J Surg 56: 676-679

20. Boulton AJM, Hardisty CA, Betts RP, Franks CI, Worth RC, Ward JD, Duckworth T (1983) Dynamic foot pressure and other studies as diagnostic and management aids in diabetic neuropathy. Diabetes Care 6: 26-33

21. Festenstein H, Adams E, Burke Y, Oliver RTD, Sachs JA, Wolf E (1972) The distribution of HLA antigens in ex-patriates from East Bengal living in London. In: Dausset J, Colombani J (eds) Histocompatibility testing. Munksgaard, Copenhagen, pp 175-178

22. Van Rood JJ, Van Loewen A, Ploem JS (1976) Simultaneous detection of two cell population by two colour fluorescence and application to the recognition of B-cell determinants. Nature 262: 795-797

23. Evans DAP (1969) An improved and simplified method of detecting the acetylator phenotype. J Med Genet 6: 405-407

24. Fluckiger R, Winterhalter KM (1976) In vitro synthesis of haemoglobin $A_{1 C}$. FEBS Lett 71:356-360

25. Fluckiger R, Harmon W, Meier W, Loo S, Gabbay KH (1981) Hemoglobin carbamylation in uremia. $\mathrm{N}$ Engl J Med 304: 823-827

26. Cudworth AG, Wolf E (1982) The genetic susceptibility to Type 1 (insulin-dependent) diabetes mellitus. In: Johnston DG, Alberti KGMM (eds) New aspects of diabetes. Clin endocrinol metab 11: 389-408

27. Barbosa JJ, Noreen H, Goetz F, Simmons R, de Leiva A, Najarian J, Yunis E (1976) Histocompatibility (HLA) antigens and diabetic microangiopathy. Tissue Antigens 7: 233-237

28. Barbosa JJ, Ramsey RC, Knobloch WC, Cantrill HL, Noreen $\mathrm{H}$, King R, Yunis E (1980) Histocompatibility antigen frequencies in diabetic retinopathy. Am J Ophthamol 90: 148-153

29. Prikhozhan VM (1977) Aetiology and pathogenesis of diabetic neuropathy. In: Prikhozhan VM (ed) Affection of the nervous system in diabetes mellitus. Mir Publishers, Moscow, pp 191-242

30. Boulton AJM, Drury J, Clarke BF, Ward JD (1982) Continuous subcutaneous insulin infusion in the management of painful diabetic neuropathy. Diabetes Care 5:386-390

Received: 31 December 1982

and in revised form: 31 October 1983

Dr. J.D. Ward

Royal Hallamshire Hospital

Sheffield S10 2JF, UK 